\title{
Computed Tomography Assessment of Coronary Fistulas
}

\author{
Laura Jáni1,2, András Mester1,2, Roxana Hodas², István Kovács¹,2, Theodora Benedek',2, Balázs \\ Bajka1,2, Imre Benedek ${ }^{1,2}$ \\ 1 University of Medicine and Pharmacy, Tîrgu Mureș, Romania \\ 2 Center of Advanced Research in Multimodality Cardiac Imaging, Cardio Med Medical Center, Tîrgu Mureș, Romania
}

\section{CORRESPONDENCE \\ Roxana Hodas \\ Str. 22 Decembrie 1989 nr. 76 \\ 540124 Tîrgu Mureș, Romania \\ Tel: +40 265217333 \\ E-mail: roxana.hodas@yahoo.ro}

\section{ARTICLE HISTORY}

Received: 16 October, 2016

Accepted: 14 December, 2016
Laura Jáni • Str. Gheorghe Marinescu nr. 38, 540139 Tîrgu Mureș, Romania. Tel: +40 265215 551. E-mail: jlaura15@yahoo.com

András Mester • Str. Gheorghe Marinescu nr. 38 540139 Tîrgu Mureș, Romania. Tel: +40 265215551. E-mail: andras.mester@yahoo.com

István Kovács • Str. Gheorghe Marinescu nr. 38 540139 Tîrgu Mureș, Romania. Tel: +40 265215551. E-mail:kov_istvan@yahoo.com

Theodora Benedek • Str. Gheorghe Marinescu nr. 38 540139 Tîrgu Mureș, Romania. Tel: +40 265215551. E-mail: theodora.benedek@gmail.com

Balázs Bajka • Str. Gheorghe Marinescu nr. 38 , 540139 Tîrgu Mureș, Romania. Tel: +40 265215551. E-mail: balazs_bajka@yahoo.com

Imre Benedek • Str. Gheorghe Marinescu nr. 38 540139 Tîrgu Mureș, Romania. Tel: +40 265215551.

E-mail: imrebedenek@yahoo.com

\begin{abstract}
Coronary artery fistulas, a rare anomaly, are represented by an abnormal communication between the coronary arteries and other vascular structures or cardiac chambers and, in most cases, are detected incidentally. Regularly, they do not cause important pathological changes, but if the symptoms persist, they need to be treated. The hemodynamic impact depends on the localization and size of the fistulas. Noninvasive imaging techniques, such as magnetic resonance imaging and multislice computed tomography, are widely used for the detection of coronary anomalies. The presence of symptoms (angina, dyspnea) is the primary indication for the surgical or percutaneous closure of the communications; therefore, a systematic follow-up is indicated in all cases. We present four cases of coronary artery fistulas, without important hemodynamic complications, detected by multislice computed tomography coronary angiography.
\end{abstract}

Keywords: coronary artery fistula, noninvasive imaging, multislice computed tomography

\section{INTRODUCTION}

Coronary artery fistulas (CAF) are considered a rare, mostly congenital abnormal connection between the coronary arteries and other vascular structures or cardiac chambers. ${ }^{1}$ In general, they do not cause important symptoms or complications, but the hemodynamic impact depends on the localization and size of the fistulas. The "coronary artery stealing" phenomenon, which leads to segmental myocardial ischemia, has low incidence rates. Other important complications include bacterial endocarditis, congestive heart failure, and even sudden death. ${ }^{2}$ New imaging techniques, such as magnetic resonance imaging (MRI) and multislice computed tomography coronary angiography (MSCT-CA), are used for detecting major coronary artery anomalies. The strengths of computed tomography (CT) are represented by faster and safer detection of abnormal coronary artery features, including origin or trajectory anomalies, as well as evaluation of the hemodynamic significance of the fistula and preoperative evaluation. ${ }^{3}$ The management and therapeutic algorithm for these coronary anomalies is dif- 

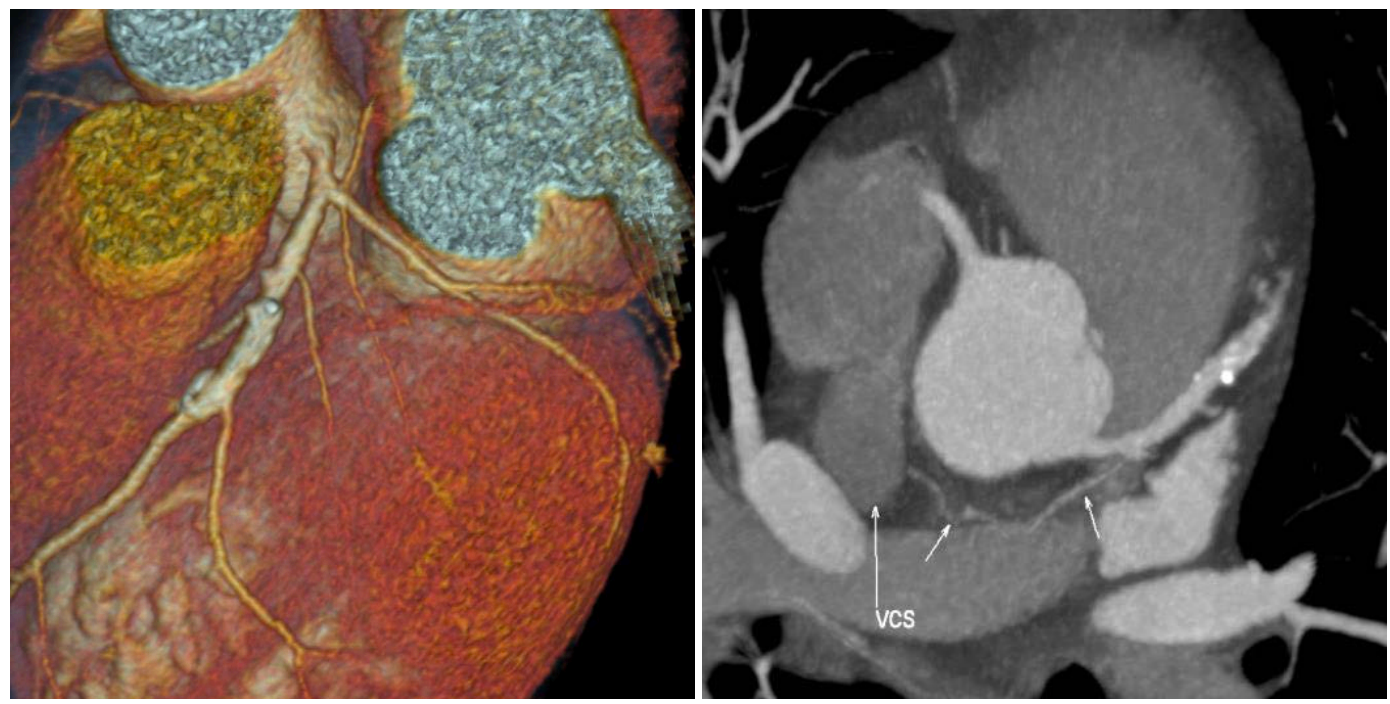

FIGURE 1. MSCT image showing a fistulous tract between proximal circumflex artery and the superior vena cava

ficult, but is only required in case of symptomatic patients. We present four cases of CAF, most of them associated with ischemic coronary disease, detected by MSCT-CA.

All patients consented to publication of their data and the publication was approved by the Ethics Committee of the center where the examinations were performed. All examinations were performed in accordance to the principles stated in the Declaration of Helsinki.

\section{CASE 1}

A 47-year-old male patient with significant cardiovascular history - acute anterior myocardial infarction and coronary angioplasty with drug-eluting stent on the left anterior descendant artery (LAD) - was admitted to the Cardiology Clinic for regular follow-up. His physical examination did not reveal any signs. The electrocardiography showed sinus rhythm with negative $\mathrm{T}$ waves in the precordial leads V1 to V6. The transthoracic echocardiogram showed a hypokinetic region in the anterior wall of the left ventricle, with a left ventricular ejection fraction of $48 \%$. The MSCT image showed the persistence of the contrast media located in the middle segment of the stent that was placed on the $\mathrm{LAD}$, associated with a calcified atheromatous plaque that did not cause a significant stenosis. The circumflex artery (CXA) and right coronary artery (RCA) did not present important lesions, but a coronary arteriovenous shunt at the emergence of the circumflex artery was found. Figure 1 illustrates the fistulous tract between the proximal circumflex artery and the superior vena cava. Considering that the patient was asymptomatic after revascularization, without chest pain, dyspnea, or fatigue, a conservative therapeutic route was chosen, with a rigorous follow-up.

\section{CASE 2}

A 59-year-old male with a history of hypertension, stroke, stable angina pectoris, and persistent atrial fibrillation that had been converted to sinus rhythm, presented to the emergency room with constrictive chest pain and fatigue occurring during minimum physical exertion. The vital signs were stable, without any pathological signs upon

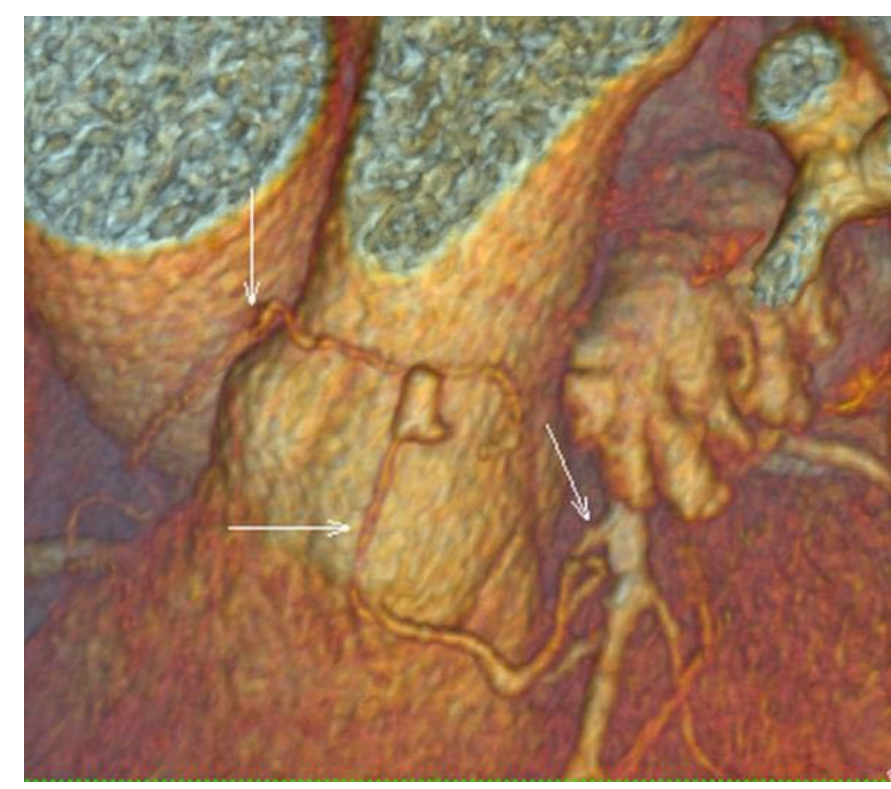

FIGURE 2. MSCT image showing multiple fistulas between proximal LAD and RCA to pulmonary trunk 

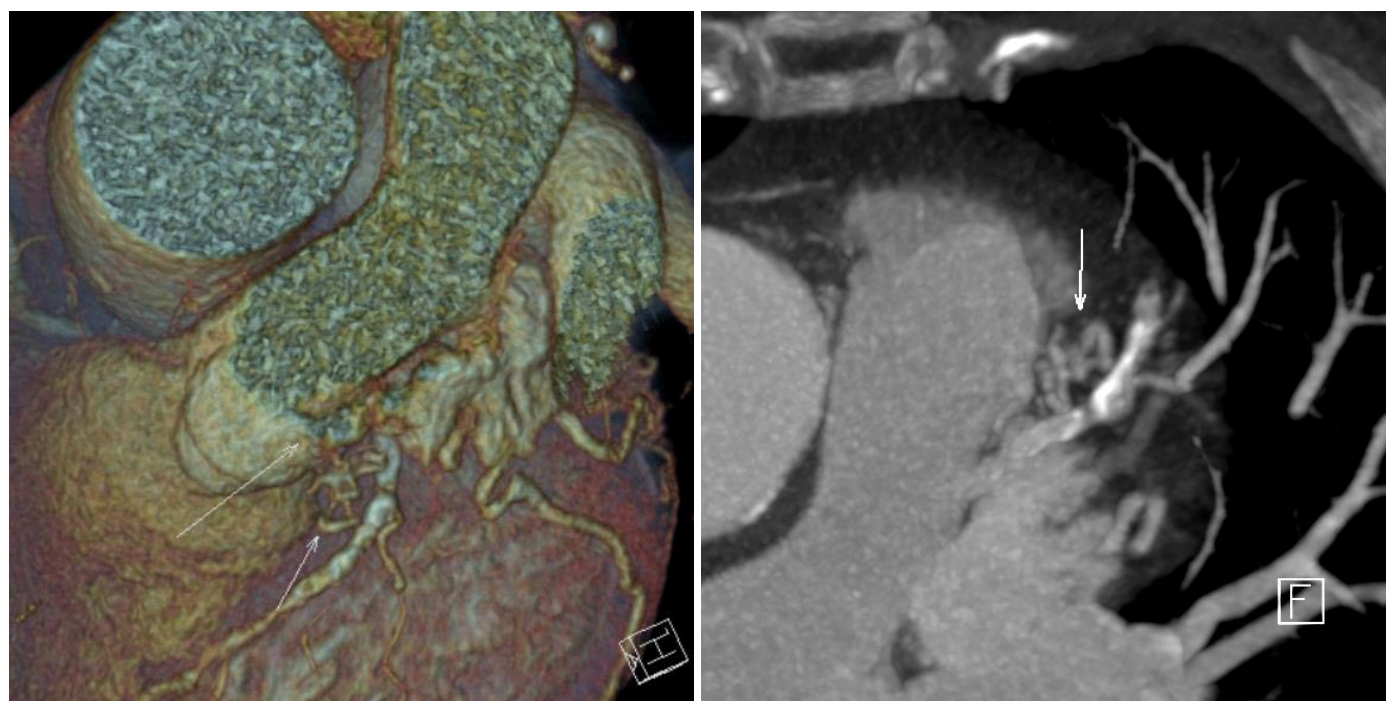

FIGURE 3. MSCT image showing fistulous tract between pulmonary trunk and left appendix

physical examination. The electrocardiography showed sinus rhythm and bifascicular block (right bundle branch block and left anterior fascicular block). The left ventricular ejection fraction was $45 \%$ as detected by transthoracic echocardiography. A MSCT-CA was performed, which detected atheromatous plaques on the $\mathrm{LAD}$, a muscle bridge - intramuscular path of the LAD, and two coronary fistulas: a coronary-pulmonary and a coronary-aortic fistula, emerging at the proximal segment of the LAD and the RCA, as shown in Figure 2. As the next step, invasive coronary angiography was performed, approaching the $60 \%$ stenosis at the proximal segment of the LAD, for which a drug eluting stent was implanted with optimal post-interventional results, with a slowed blood flow in the direction of the coronary-aortic fistula.

\section{CASE 3}

A 84-year-old female patient with a history of hypertension and various episodes of retrosternal chest pain with burning character was admitted to our department. Physical examination revealed a systolic murmur at the left sternal border. Electrocardiography showed a left bundle branch block, and the laboratory tests were without any pathological changes. The echocardiographic image showed a hypokinetic left ventricular anterior wall. Cardiac MSCT
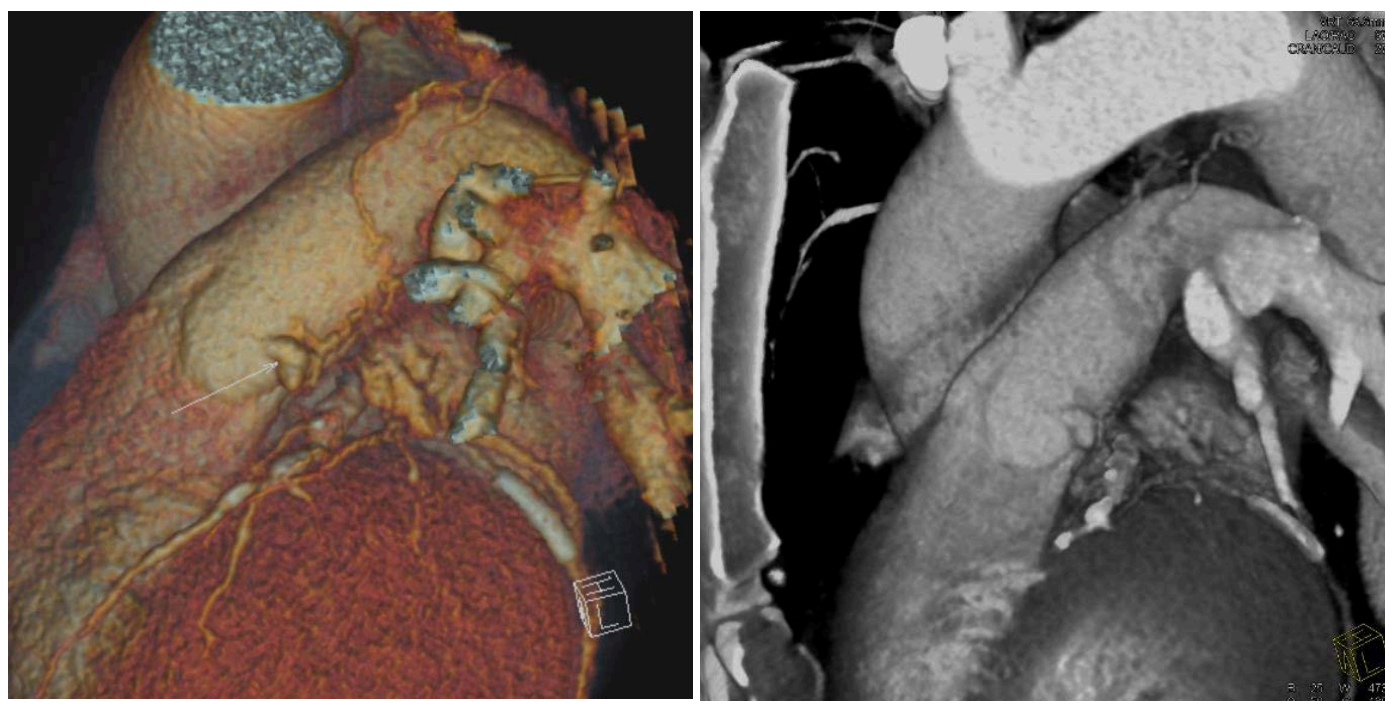

FIGURE 4. MSCT images showing multiple fistulas between aortic arch and pulmonary trunk 
revealed moderate stenotic lesions on the LAD and a communication between the pulmonary trunk and the left atrial appendage, as illustrated in Figure 3. The management of this case included the use of pharmacological agents with favorable evolution of symptoms.

\section{CASE 4}

A young, 46-year-old male patient, with recent inferior myocardial infarction for which a primary percutaneous coronary angioplasty with a drug eluting stent on the RCA was performed, presented for the 1-year follow-up. The patient was complaining of chest pain and dyspnea occurring after minimum physical exertion. The electrocardiography showed negative T waves in DII and DIII leads, and the echocardiogram revealed a normal left ventricular ejection fraction. An invasive coronary angiography was performed, and it revealed a $65 \%$ stenosis on the LAD and critical stenosis on the circumflex artery. The patient underwent a coronary angioplasty with a drug-eluting stent in the middle segment of the CXA, with optimal post-procedural results. During the coronary intervention, multiple small fistulas connecting the left anterior descending artery with the pulmonary trunk were observed. For a more detailed image acquisition, an MSCT-CA was also performed, which described multiple aorto-pulmonary fistulas up to $2 \mathrm{~mm}$ in diameter, between the aortic arch and the pulmonary artery (Figure 4).

\section{DISCUSSIONS}

Coronary artery fistulas represent $0.2-0.4 \%$ of congenital cardiac anomalies. ${ }^{4}$ A single communication or multiple fistulas between two vascular structures or between a coronary artery and a cardiac chamber have been described. ${ }^{5}$ In most cases, fistulas are associated with other cardiac anomalies such as persistent ductus arteriosus or vascular atresia.

From a pathophysiological point of view, CAF are characterized by a reduction in the myocardial blood flow distal to the fistulous tract, the so-called "myocardial stealing". The diastolic pressure gradient is modified by the quantity of blood lost due the communications. ${ }^{6}$ The existence of a fistula is compensated by the enlargement of the artery that leads to the fistula, with several possible complications such as aneurysm development, atherosclerotic deposition, and even rupture in a few cases. The pressure difference between the feeding artery and the recipient structure influences the severity of the shunt; the largest shunts have been detected in cases where the right side of the heart was affected.
Adult patients are in most cases asymptomatic, but the clinical presentation depends on the localization, the size of the communication, and the resistance of the recipient structure. The possible symptoms include chest pain, arrhythmias, dyspnea or fatigue. ${ }^{7}$ During physical examination of these patients, a specific systolic and diastolic murmur might also be detected. ${ }^{8}$

The most used noninvasive diagnostic tools in case of suspicioning these coronary anomalies are transthoracic or transesophageal echocardiography, multislice computed tomography, and magnetic resonance imaging. ${ }^{9}$ Invasive angiography also offers detailed information about the type of the fistula - solitary or multiple, about the recipient vessel or chamber, but in most cases, it is used as a preoperative evaluation method, similarly to transesophageal echocardiography. ${ }^{10}$

MSCT-CA is a useful and fast imaging technique that allows certain anatomic descriptions, with some limitations that include radiation exposure. ${ }^{11}$

The management of asymptomatic patients is represented by rigorous, periodic follow-up. ${ }^{12}$ The presence of specific symptoms and large shunts are indications for closure of the communication. This can be achieved by two methods: surgical - ligation, or interventional - transcatheter embolization. ${ }^{13}$ Surgical ligation of the fistula was the primary treatment option until the 80 's, when the percutaneous method has been introduced. ${ }^{14}$ The transcatheter closure is performed using various devices such as occlusion coils or umbrella devices. ${ }^{15}$ Indications for the percutaneous embolization are: draining location in one heart site, proximal location of the fistula, absence of associated cardiac pathology that would require surgical correction. ${ }^{16}$ After transcatheter closure, antiplatelet therapy and low-dose anticoagulation are required, as well as a long-term follow-up. ${ }^{17}$

\section{CONCLUSIONS}

Detection of these rare coronary anomalies is incidental in most cases. Noninvasive assessment, such as magnetic resonance imaging or multislice computed tomography, are widely available, offer safe information, thus helping in the management of coronary fistulas. The presence of symptoms (angina, dyspnea) is the primary indication for surgical or percutaneous closure of the fistulas. Long-term periodic, rigorous follow-up is highly recommended in all cases.

\section{CONFLICT OF INTEREST}

Nothing to declare. 


\section{ACKNOWLEDGEMENT}

This research was supported via the research grant no. 103545/2016, contract number 43/05.09.2016, entitled "High performance multimodal MRI/CT imagingplatform, for applications in computational medicine, nanoparticles and hybrid imaging for the research of atherothrombotic disorders - CARDIO IMAGE" financed by the Romanian Ministry of European Funds, the Romanian Government and the European Union.

\section{REFERENCES}

1. Karazisi C, Eriksson P, Dellborg M. Coronary artery fistula: A case series with review of the literature. Cardiology. 2017;136:93-101.

2. Gowda RM, Vasavada BC, Khan IA. Coronary artery fistulas: clinical and therapeutic considerations. Int J Cardiol. 2006;107:7-10.

3. Schmitt R, Froehner S, Brunn J, et al. Congenital anomalies of the coronary arteries: imaging with contrast-enhanced, multi-detector computed tomography. Eur Radiol. 2005;15:1110-1121.

4. Gupta M. Coronary Artery Fistula. Available at: http://emedicine.medscape. com/article/895749-overview?pa=a4HZNEP9BUq1\%2BeO\%2FRpvvtsZRz nWH\%2BZuGJDTQ8\%2F3lu8egV8LfRNBpI9nchgA7IITBaaNejBeLXDEwX cty5ZYj\%2FTRbGMQ7s\%2F89oYHt2gMBBbM\%3D\#a5
5. Cemri M, Sahinarslan A, Akinci S, Arslan U. Dual coronary artery-pulmonary artery fistulas. Can J Cardiol. 2009;25:e95.

6. Schamroth C. Coronary artery fistula. J Am Coll Cardiol. 2009;53:523.

7. Said SA, van der Werf T. Dutch survey of coronary artery fistulas in adults: congenital solitary fistulas. Int J Cardiol. 2006;106:323-332.

8. Haller Jr JA, Little JA. Diagnosis and surgical correction of congenital coronary artery-coronary sinus fistula. Circulation. 1963;27:939-942.

9. Armsby LR, Keane JF, Sherwood MC, Forbess JM, Perry SB, Lock JE. Management of coronary artery fistulae. Patient selection and results of transcatheter closure. Am J Coll Cardiol. 2002;39:1026-1032.

10. lida R, Yamamoto T, Suzuki T, Saeki S, Ogawa S. The usefulness of intraoperative transesophageal echocardiography to identify the site of drainage of coronary artery fistula. Anesth Analg. 2005;101:330-331.

11. Nakamura M, Matsuoka H, Kawakami H, et al. Giant congenital coronary artery fistula to left brachial vein clearly detected by multi-detector computed tomography. Circ J. 2006:70:796-799.

12. Said SA, Lam J, van der Werf T. Solitary coronary artery fistulas: a congenital anomaly in children and adults. Congenit Heart Dis. 2006:1:63-76.

13. Latson LA. Coronary artery fistulas: how to manage them. Catheter Cardiovasc Interv. 2007;70:110-116.

14. Reidy JF, Sowton E, Ross DN. Transcatheter occlusion of coronary to bronchial anastomosis by detachable balloon combined with coronary angioplasty at same procedure. Br Heart J. 1983;49:284-287.

15. Xu L, Xu ZY, Jiang SL, et al. Transcatheter closure of coronary artery fistula in children. Chin Med J (Engl). 2010;123:822-826.

16. Mavroudis C, Backer CL, Rocchini AP, Muster AJ, Gevitz M. Coronary artery fistulas in infants and children: a surgical review and discussion of coil embolization. Ann Thorac Surg. 1997;63:1235-1242.

17. McMahon CJ, Nihill MR, Kovalchin JP, Mullins CE, Grifka RG. Coronary artery fistula. Management and intermediate term outcome after transcatheter coil occlusion. Tex Heart Inst J. 2001:28:21-25. 